\title{
Application of digital technologies in criminological grading of the correctional facility
}

\author{
Sergey Ponomarev*, and Dmitry Ponomarev \\ Research Institute of the Federal Penitentiary Service of Russia, 125130 Moscow, Russia
}

\begin{abstract}
The article discusses the relevance of the information systems metrological support. The information systems that are related to human security in society were studied. The article analyzes the problem of the criminal subculture development in society and the possibility of metrological support for its estimation. That problem has been studied on the example of the information system for assessing the criminal subculture in the penal system of the Russian Federation development. A metrological study has been carried out. A point system has been created for parameters that characterize the level of the criminal subculture evolution. The use of the method of expert assessments in the experiments is proposed, which significantly increases the level of reliability of research results.
\end{abstract}

\section{Introduction}

The problem of the spread of crime in the Russian Federation is one of the most urgent at the present time. There are many methods of preventing the influence of criminal communities spreading, but at the moment there is no general gradation in points equivalent to determine the level of criminal subculture prevalence [1].

The manifestation of the criminal subculture in society can be expressed not only in the form of compliance with criminal norms and rules [2], but also in the expression of such important parameters such as:

1. the possibility of criminals resocialization,

2. involvement in extremist activities and unlawful actions,

3. suicidal behavior,

4. interaction with the penal system staff.

The important problem is the expression of the indicated parameters in a numerical equivalent. Therefore, the problem of organizing metrological support and the development of an information system $[3,4]$ based on it is important and poorly studied.

\section{Methods}

In the article, an analysis was carried out and the reflection in the point (numerical) equivalent of the criminal sentiments spread in society was proposed. The experimental study was carried out within the framework of the penal system. A study was conducted among penal

\footnotetext{
* Corresponding author: ponomarev.dmitry1990@ mail.ru
} 
system staff who directly interacted with members of organized crime. Based on the data obtained, the organization of metrological support for determining the level of criminalization in society was carried out. After that, the results were combined into the information system, which allows assessing the development of crime in society. In this work, a method of expert assessments was introduced. The method of expert assessments was based on the organization of metrological support of the using parameters [5-8]. The penal system staff were considered as experts to assess the respondents' adherence to the criminal subculture. A prerequisite was that the officer-expert interacted directly with the respondents repeatedly and stably. For the experts, questions were created to which the respondents themselves may give a knowingly false answer.

In addition, for the subsequent development of prognostic models, the opinion of experts should be taken into account not only in points, but also in numerical equivalence [9]. Therefore, for the experts, a formula was used for the measurement in the numerical equivalent of 1 indicator of 1 questioned prisoner.

$$
A_{i}=\frac{n}{m}
$$

where:

$A_{i}$ - numerical term of one indicator which is set by the expert to one respondent;

$n$ is the number of the answer level;

$m$ - the number of proposed answers to the question posed, which characterizes the indicator under study.

Table 1 shows a number of questions that characterize the level of each parameter. A point grading of these questions is proposed. According to formula 1, it is proposed to express in a numerical equivalent each of the parameters under study.

Table 1. Determination of numerical coefficients of indicators, reflected the criminal subculture spreading, based on expert opinion.

\begin{tabular}{|c|c|c|c|c|}
\hline Indicator & Answers & $N$ & $m$ & $A_{i}$ \\
\hline \multirow{3}{*}{$\begin{array}{c}\text { Willingness to interact } \\
\text { with the administration } \\
\text { of the correctional } \\
\text { institution }\end{array}$} & Choose the interaction independently & 3 & \multirow{3}{*}{3} & 1 \\
\hline & Choose the interaction without initiative & 2 & & 0.67 \\
\hline & Doesn't cooperate & 1 & & 0.33 \\
\hline \multirow{3}{*}{ Suicidal behavior } & no suicidal behavior & 3 & \multirow{3}{*}{3} & 1 \\
\hline & demonstrative manifestation of suicidal behavior & 2 & & 0.67 \\
\hline & attempts of real suicide & 1 & & 0.33 \\
\hline \multirow{4}{*}{$\begin{array}{l}\text { Involvement in } \\
\text { extremist activities }\end{array}$} & No involvement in extremist activities & 4 & \multirow{4}{*}{4} & 1 \\
\hline & Low level of involvement in extremist activities & 3 & & 0.75 \\
\hline & $\begin{array}{l}\text { Medium level of involvement in extremist } \\
\text { activities }\end{array}$ & 2 & & 0.5 \\
\hline & High level of involvement in extremist activities & 1 & & 0.25 \\
\hline \multirow{4}{*}{$\begin{array}{l}\text { Involvement in illegal } \\
\text { actions }\end{array}$} & No illegal actions & 4 & \multirow{4}{*}{4} & 1 \\
\hline & Low level of involvement in illegal actions & 3 & & 0.75 \\
\hline & Medium level of involvement in illegal actions & 2 & & 0.5 \\
\hline & High level of involvement in illegal actions & 1 & & 0.25 \\
\hline \multirow{4}{*}{$\begin{array}{l}\text { Resocialization } \\
\text { possibility }\end{array}$} & High level of resocialization possibility & 4 & \multirow{4}{*}{4} & 1 \\
\hline & Medium level of resocialization possibility & 3 & & 0.75 \\
\hline & Low level of resocialization possibility & 2 & & 0.5 \\
\hline & No opportunity & 1 & & 0.25 \\
\hline
\end{tabular}




\section{Results}

Based on table 1, let's analyze each of the parameters and the proposed variants of its rating.

Interaction with the penal system staff to prevent and reduce illegal actions. The first thing to be assessed is the convict's willingness to interact with the penal system staff. Here several answer options can be distinguished. First: the prisoner doesn't interact with the jail staff. In other words, the prisoner does not interact in any way with the officers of the penal system to prevent and reduce illegal actions.

The second - choose the interaction with the jail staff, but does not show excessive initiative. This implies that the inmate does not contact the prison staff to prevent and reduce unlawful actions until the staff themselves refer to that prisoner. Third, the prisoner chooses active cooperation independently, i.e. he takes the initiative to prevent and reduce illegal activities in the penal system.

Suicidal behavior as an opportunity to influence society and suicidal danger. The next important indicator is the suicidal behavior of the convicted person as a way of pressure on the penal system staff. Note that here we are considering suicidal behavior as a method of psychological pressure on penal system staff, and not directly as a suicide itself (which, as a rule, is planned secretly not only from staff, but also from other inmates). That is why suicidal behavior (in the context of influencing the penitentiary system staff) was classified as illegal action. Possible answers for experts in this case may be as follows:

first - inmate not prone to suicidal behavior i.e. penal system officers have no reason to think that this prisoner may commit suicide;

second, inmate is prone to demonstrative manifestation of suicidal behavior, i.e. there are may be demonstrative cutting of veins, shouts of suicide, numerous unsuccessful attempts at hanging, accompanied by hysterical inappropriate behavior with a possible manifestation of aggression;

the third is a tendency to true suicidal behavior - here in most cases there is a closed personality, alienation from society, a person is "in himself", outbreaks of baseless aggression, melancholy, apathy, depression, lethargy without apparent reasons for deterioration of physical health are possible.

Involvement in extremist activities and illegal actions [10,11]. This parameter is assessed by an expert based on the general behavior of inmates. The following options are possible.

The first is the lack of involvement in extremist activities, characterized by the fact that the convicted person will not take part in extremist activities even under pressure from the environment.

The second is a low level of involvement in extremist activities, characterized by the fact that prisoners can take part in extremist activities under pressure of the environment.

The third is the middle level of involvement, i.e. prisoners independently, without pressure from the environment, can take part in extremist activities, if appropriate conditions arise.

Fourth, a high level of involvement, prisoners can put pressure on prisoners and act as an organizer of an extremist organization i.e. in fact he is the leader of extremist activity.

To measure the involvement of prisoners in illegal actions, the following gradation was made.

The first is the lack of involvement of inmates in illegal activities, i.e. the convicted person will not take part in illegal actions even under pressure from the environment.

The second is the low level of prisoner participation in illegal activities, i.e. convicts can take part in a riot under pressure from the environment.

The third is the middle level of participation of convicts in illegal actions, in other words, prisoners can independently, without pressure from their environment and leaders, take part in a riot, if the appropriate conditions arise. 
Fourth - a high level of illegal actions: convicted people can provoke conflict situations, organize a set of illegal actions in prison.

The possibility of resocialization of the convict as a parameter of reducing social danger. Resocialization in that context is the ability of prisoner of society adaptation after release from prisons.

As everybody knows, social danger is the result of a long absence of social ties and a lack of human adaptation in society. A person who cannot adapt in modern society begins to oppose himself to this society, and the criminal subculture is one of the most optimal tools for this opposition. In other words, the lack of resocialization or its low level can cause new offenses, the increase of social danger, and the increase of illegal actions.

Therefore, this parameter is especially important if we are not talking about social danger at the moment, but about its development in the future (i.e., for the subsequent prevention of possible crimes and illegal actions).

To determine the level of resocialization of the convict, several levels are proposed.

The first level is the lack of opportunity (lack of social ties and the possibility of their restoration, except for those in the criminal (prison) environment);

the second is a weak opportunity (social ties are broken, but can be restored on condition of post-penitentiary support, including social support measures (employment, provision of social housing, etc.);

the third is the middle level of the resocialization possibility (social ties are partially preserved and a person can be adapted in society in the case of providing social support);

the fourth is a high possibility of resocialization (social ties are preserved, a person is able to adapt in society).

\section{Discussion}

The results can be applied to the development of mathematical models. Models based on artificial neural networks are very popular. It seems relevant to consider the parameters of suspects, accused and convicted persons as input signals. As an outgoing signal, it is necessary to take the danger of a person to society, which is expressed in a numerical equivalent according to the described methodology. The use of artificial neural networks for the described problem can be implemented in the future as follows. For the spreading of incoming signals, apply the formula (2) [12]:

$$
X=W I
$$

where: $W$ is the matrix of weights of the artificial neural network; $I$ - matrix of input signals; $X$ - the resulting matrix for the neurons of the hidden layer. The passage of an incoming signal for a neural network (using the example of an ANN with one hidden layer and three incoming signals) will look like this (3):

$$
\left(\begin{array}{l}
I_{1} \\
I_{2} \\
I_{3}
\end{array}\right)\left(\begin{array}{lll}
w_{11} & w_{21} & w_{31} \\
w_{12} & w_{22} & w_{32} \\
w_{13} & w_{23} & w_{33}
\end{array}\right)=\left(\begin{array}{l}
x_{1} \\
x_{2} \\
x_{3}
\end{array}\right)
$$

where $w$ are the weights of the artificial neural network; $I_{1}, I_{2}, I_{3},-$ input signals; $x-$ signals that go to each neuron. In addition, the neuronal activation function should be considered. There are several activation functions. The most popular are tangential and sigmoidal. For example, a sigmoidal activation function would look like this: (4):

$$
f(s)=\frac{1}{1+e^{-\alpha}}
$$


where $\alpha$ is the sum of signals arriving at the hidden layer neuron, $f(s)$ is the outgoing signal for each hidden layer neuron. The formula for back propagation of the error is formed based on the selected activation function and the structure of the artificial neural network. For example, the back propagation of an error for an artificial neural network with one hidden layer will look like this (5) [12]:

$$
\frac{d E}{d w_{j k}}=-\left(t_{k}-o_{k}\right) \frac{1}{1+e^{\sum_{j} w_{j k} o_{j}}}\left(1-\frac{1}{1+e^{\sum_{j} w_{j k} o_{j}}}\right) o_{j}
$$

where $t_{k}$ is the actual value that corresponds to the output of the ANN, $o_{k}$ is the output signal (output) of the ANN, $w_{j k}$ are the weight values f the ANN connections, $o_{j}$ is the output signal of the hidden layer, $E$ is the total layer error, due to which the ANN weights are corrected.

Applying all the above formulas and algorithms, it is possible to develop a model that will, according to the primary parameters of suspected, accused and convicted persons (such as education level, number of convictions, term of imprisonment, etc.), identify their danger to society and the possibility of repeated crimes.

\section{Conclusion}

Thus, the parameters were selected and scientifically substantiated that most of all have an impact and characterize the social danger of the individual, his adherence to the criminal subculture and criminal actions.

A number of questions were created for expert opinion about the respondents, and a point score was created for each of the studied parameters. An information system has been developed, which is based on the organization of metrological support of the parameters under study.

The proposed system allows you to rank all the parameters under study in the numerical range from 0 to 1 . This is especially convenient when developing mathematical models and information systems.

\section{References}

1. S. B. Ponomarev, D. S. Ponomarev, V. E. Polishchuk, A. A. Burt, European Proceedings of Social and Behavioural Sciences EpSBS 90, 1588 (2020)

2. D. S. Ponomarev, S. B. Ponomarev, N. V. Rumyantsev, S. H. Shamsunov, M. U. Tarasov, EurAsian Journal of BioSciences 14(2) 5727-30 (2020)

3. L. Bertalanffy, C. G. Hempel, H. Jonas, Human Biology 23, 303 (1951)

4. S. B. Ponomarev, D. S. Ponomarev, V. E. Polishchuk, A. A. Burt, E. V. Dyuzheva, Journal of Physics: Conference Series 1399, 33027 (2019)

5. E. Förster, B. Rönz, Finance and Statistics, 151 (1983)

6. R. R. Guliev, O. V. Senko, D. A. Zateyshchikov, V. V. Nosikov, I. V. Uporov, A. V. Kuznetsova, Mathematical Biology and Bioinformatics 1, 46 (2016)

7. V. I. Sergienko, I. B. Bondareva, Mathematical statistics in clinical studies 1, 304 (2006)

8. N. Draper, G. Smith, Regression analysis. Multiple regression Dialectics, 912 (2007)

9. S. B. Ponomarev, D. S. Ponomarev, V. E. Polishchuk, A. A. Burt, E. L. Averyanova, JOP Conference Series: Metrological Support of Innovative Technologies 1515, 52036 (2020) 
10. B. Western, American Sociological Review 67(4), 526 (2002)

11. L. Monakhova, M. Smirnov, P. Starygina, O. Timofeeva, Espacios 38(52), 36 (2017)

12. Tariq Rashid, 2016 Make Your Own Neural Network, 76 (2016) 